\title{
Métodos de Superação de DoRmênCIA em Sementes de Ipomoea E Merremia ${ }^{1}$
}

\author{
Dormancy Breaking Methods in Ipomoea and Merremia Seeds
}

AZANIA, A.A.P.M. ${ }^{2}$, AZANIA, C.A.M. ${ }^{2}$, PAVANI, M.C.M.D. ${ }^{3}$ e CUNHA, M.C.S. ${ }^{4}$

\begin{abstract}
RESUMO - Este trabalho objetivou avaliar os efeitos de métodos de superação de dormência sobre a germinação das sementes de Ipomoea grandifolia, I. hederifolia, I. nil, I. quamoclit, Merremia aegyptia e $M$. cissoides. Os tratamentos consistiram em ácido sulfúrico concentrado, nitrato de potássio, água quente e calor seco $\left(50^{\circ} \mathrm{C}\right)$, lixa e fogo. Constatou-se que o ácido sulfúrico promoveu aumento na germinação das sementes de I. grandifolia (58, 37, 22 e $34 \%)$, I. hederifolia (76, 49, 82 e 55\%), I. quamoclit (43, 33, 66 e 35\%), I. nil (69, 79, 72 e 62\%), $M$. cissoides $(8,19,35$ e 57\%) e $M$. aegyptia $(24,64,56$ e 63\%) após períodos de imersão de 5, 10, 15 e 20 minutos, respectivamente. A água (20 e 40 minutos), o calor seco (20 e 40 minutos) e o fogo melhoraram a germinação de $I$. grandifolia $(68,59,62,67$ e 59\%), M. cissoides (50, 52, 18, 25 e 46\%) e $M$. aegyptia (54, 47, 21, 21 e 45\%), respectivamente. O calor seco de 20 e 40 minutos melhorou a germinação de I. nil (49 e 36\%), e o de 40 minutos, a de $I$. hederifolia (70\%). O uso de nitrato de potássio e lixa não proporcionou melhoria na germinação das sementes.
\end{abstract}

Palavras-chave: Convolvulaceae, escarificação, germinação.

\begin{abstract}
This research aimed to evaluate the effects of dormancy breaking methods on germination of Ipomoea grandifolia, I. hederifolia, I. nil, I. quamoclit, Merremia aegyptia and $\boldsymbol{M}$. cissoides seeds. The treatments consisted of concentrated sulfuric acid, potassium nitrate, and mechanical and physical scarification for fire, water and dry heat at $50{ }^{\circ} \mathrm{C}$. The sulfuric acid increased seed germination of I. grandifolia (58, 37, 22 and $34 \%)$, I. hederifolia (76, 49, 82 and 55\%), I. quamoclit (43, 33, 66 and 35\%), I. nil (69, 79, 72 e 62\%), M. cissoides (8, 19, 35 and 57\%) and M. aegyptia (24, 64, 56 and 63\%) after 5, 10, 15 and 20 min, respectively. Water (20 and $40 \mathrm{~min})$, dry heat $(20$ and $40 \mathrm{~min}$ ) and fire increased germination of I. grandifolia (68, 59, 62, 67 and 59\%), M. cissoides (50, 52, 18, 25 and 46\%) and M. aegyptia (54, 47, 21, 21 and 45\%), respectively. Dry heat (20 and $40 \mathrm{~min}$ ) increased seed germination of I. nil (49 and 36\%) and (40min) of I. hederifolia (70\%). Potassium nitrate and sandpaper did not increase seed germination.
\end{abstract}

Key words: Convolvulaceae, scarification, germination.

\section{INTRODUÇÃO}

As espécies de Ipomoea grandifolia I. hederifolia, Ipomoea quamoclit, Ipomoea nil, Merremia cissoides e Merremia aegyptia são plantas que pertencem à família Convolvulaceae, sendo conhecidas popularmente como corda-de-viola, campainha, etc. Essas plantas são apreciadas como ornamentais, por apresentarem flores vistosas e intensamente coloridas; pelo fato de crescerem sobre obstáculos, são usadas também para cobrir caramanchões. Entretanto, essas plantas tornaram-se importantes infestantes em diferentes culturas,

Recebido para publicação em 24.6.2002 e na forma revisada em 11.8.2003.

2 Pós-graduando em Produção Vegetal da Faculdade de Ciências Agrárias e Veterinárias - FCAV/UNESP, Rod. Paulo D. Castelane, Km 5, 14870-000 Jaboticabal-SP; ${ }^{3}$ Profa. Dra. do Dep. de Biologia Aplicada à Agropecuária da FCAV/UNESP; ${ }^{4}$ Graduando em Engenharia Agronômica da FCAV/UNESP. 
dificultando principalmente a colheita (Kissmann \& Groth, 1992; Lorenzi, 2000). Portanto, seja para finalidades ornamentais ou controle das culturas, as plantas de Ipomoea e Merremia devem ter a biologia mais bem estudada.

A execução de alguns desses estudos pode ser comprometida devido à dormência das sementes de algumas espécies, o que, segundo Carmona (1992), dificulta a obtenção de estandes uniformes de plantas. Dentre as principais causas da dormência na maioria das espécies destaca-se a impermeabilidade do tegumento à água (Felipe \& Polo, 1983), por causa da formação de uma camada paliçádica de microsclereídeos ou células de Malpighi impregnadas com suberina, cutina e lignina, de pouca afinidade com a água (Rolston, 1978).

A germinação da semente somente é possivel quando ocorrer uma abertura pela camada paliçádica (Baskin \& Baskin, 1989). A impermeabilidade do tegumento nas sementes das plantas de Ipomoea e Merremia se constitui em um mecanismo de sobrevivência, permitindo que as sementes permaneçam anos sem germinar (Chandler et al., 1977).

Em Convolvulaceae, Stoller \& Wax (1974) constataram que o uso de ácido sulfúrico destacou-se como método de superação de dormência, apresentando 100\% de germinação para Ipomoea hederacea. Para Hardcastle (1978), o uso de ácido sulfúrico durante 30 e 120 minutos proporcionou 53,6 e $97,2 \%$ de germinação para Ipomoea obscura, respectivamente. Horak \& Wax (1991) também constataram que a germinação de Ipomoea pandurata foi superior a $80 \%$ quando as sementes foram imersas em ácido sulfúrico durante 20 a 80 minutos. Para Ogunwenmo \& Ugborogho (1999), o ácido sulfúrico concentrado proporcionou $100 \%$ de germinação para Ipomoea obscura, Ipomoea aquatica e Ipomoea hederifolia, enquanto para Ipomoea sinensis ele não foi eficaz na germinação (Moaisi \& Phillips, 1991).

O calor seco e a imersão em água quente constituem outros métodos de superação de dormência, pois, segundo Kim et al. (1990), proporcionaram 65 e $70 \%$ de germinação para sementes de Commelina benghalensis, quando expostas a $90^{\circ} \mathrm{C}$ durante quatro horas e imersas em água a $70{ }^{\circ} \mathrm{C}$ durante um minuto, respectivamente. Segundo os autores, o calor provocou fendas na superfície da semente, permitindo a entrada de água e, conseqüentemente, a germinação. Em Ipomoea lacunosa, Egley (1990) observou que em areia aquecida de 40 a $60{ }^{\circ} \mathrm{C}$, na presença ou ausência de umidade, as sementes sobreviveram e apresentaram aumento na germinação devido à quebra de dormência. De acordo com Moaisi \& Phillips (1991), a água quente $\left(40^{\circ} \mathrm{C}\right)$ não estimulou a germinação de Ipomoea sinensis mesmo quando as sementes foram imersas por 24 horas.

O uso de nitrato de potássio ( 9 e 15 horas de imersão) não proporcionou aumento na germinação de Ipomoea sinensis, mas a escarificação mecânica (corte ou perfuração do tegumento) foi efetiva na germinação da espécie (Moaisi \& Phillips, 1991). Segundo Ogunwenmo \& Ugborogho (1999), a escarificação mecânica também foi eficiente em Ipomoea obscura, Ipomoea aquatica, Ipomoea hederifolia e Ipomoea involucrata.

Com o intuito de diminuir os efeitos da camada impermeável das sementes de Convolvulaceae sobre a germinação, objetivouse avaliar a eficácia de diferentes métodos de superação de dormência na germinação das sementes de Ipomoea grandifolia, I. hederifolia, I. nil, I. quamoclit, Merremia aegyptia e M. cissoides.

\section{MATERIAL E MÉTODOS}

O experimento foi conduzido em laboratório na Faculdade de Ciências Agrárias e Veterinárias de Jaboticabal, utilizando-se sementes de Ipomoea grandifolia, Ipomoea nil, Ipomoea quamoclit, Merremia cissoides e Merremia aegyptia. As sementes livres de impurezas sofreram tratamento químico e escarificação química, física e mecânica, como métodos de superação de dormência, antes de se avaliar a germinação.

O tratamento químico foi proporcionado pela imersão das sementes em solução de nitrato de potássio $(0,2 \% \mathrm{v} / \mathrm{v})$ durante 6,12 , 18 e 24 horas, e a escarificação química, por ácido sulfúrico concentrado durante 5, 10, 15 e 20 minutos, ambos com as sementes agitadas ocasionalmente, lavadas em água corrente, secas à sombra e em temperatura ambiente. 
A escarificação física com água ou exposição ao calor seco $\left(50^{\circ} \mathrm{C}\right)$ deu-se pela imersão das sementes em béquer com e sem água, respectivamente, sobre uma placa aquecedora a $50{ }^{\circ} \mathrm{C}$ por 20 e 40 minutos; posteriormente elas foram secas e/ou resfriadas à sombra e temperatura ambiente. A escarificação física com fogo deu-se pelo enterrio das sementes a $1,5 \mathrm{~cm}$, em vasos de concreto com $60 \mathrm{~cm}$ de diâmetro, e cobertos com o equivalente a $15 \mathrm{t} \mathrm{ha}^{-1}$ de palha de cana-de-açúcar, com posterior ateio de fogo na palha, recuperação e resfriamento das sementes em temperatura ambiente.

A escarificação mecânica foi feita esfregando manualmente as sementes entre duas lâminas de lixas de parede número 150 , durante 20 segundos.

O delineamento experimental utilizado foi o inteiramente casualizado, com 15 tratamentos e quatro repetições, para cada espécie separadamente. Os tratamentos constituíramse das sementes submetidas aos diferentes tempos e métodos de escarificação química, física e mecânica, além da testemunha (sem qualquer escarificação). As parcelas foram constituídas por 100 sementes de uma mesma espécie, que foram colocadas em placas de plástico previamente desinfetadas, preparadas com papel-filtro autoclavado e levadas para câmara de germinação a $30 / 20^{\circ} \mathrm{C} \mathrm{e} 14 / 10$ horas de presença e ausência de luz, respectivamente. A análise de variância pelo teste $\mathrm{F}$, de acordo com o delineamento inteiramente casualizado, foi utilizada para avaliar o efeito dos tratamentos sobre as variáveis analisadas; posteriormente, na comparação das médias dos tratamentos, utilizou-se o teste de Tukey a 5\% de probabilidade.

A superação da dormência das sementes testadas foi avaliada pela contagem diária do número de sementes germinadas com comprimento de raiz superior a $2 \mathrm{~mm}$, durante 15 dias; posteriormente, pela determinação da porcentagem de germinação, foi feito o cálculo do índice de velocidade de germinação (IVG), segundo Maguire (1962).

\section{RESULTADOS E DISCUSSÃO}

Entre todos os métodos testados para promover a quebra de dormência das sementes das diferentes espécies de Ipomoea e Merremia, constatou-se que o uso de ácido sulfúrico concentrado proporcionou maiores ocorrências de germinação em todas as espécies testadas, exceto o tratamento com 15 minutos de exposição para I. grandifolia; com 5, 10 e 20 minutos para I. quamoclit; e com 5 minutos para $M$ cissoides e $M$. aegyptia. Entretanto, os tratamentos com nitrato de potássio e com a lixa de parede foram os métodos menos eficazes na quebra de dormência para todas as espécies. Os tratamentos que envolveram a temperatura apresentaram aumento nos percentuais de germinação de algumas espécies quando estas foram imersas em água durante 20 ou $40 \mathrm{mi}-$ nutos (I. grandifolia, M. cissoides e M. aegyptia), calor seco a 20 e 40 minutos (I. grandifolia, I. hederifolia, $I$. nil e $M$. cissoides) e fogo (I. grandifolia, M. cissoides e M. aegyptia) (Figura 1).

Os tratamentos com exposição das sementes ao ácido sulfúrico (Figura 1) aumentaram o percentual de germinação de I. grandifolia (5, 10 e 20 minutos), I. hederifolia $(5,10,15$ e 20 minutos), I. quamoclit (15 minutos), I. nil (5, 10,15 e 20 minutos), $M$. cissoides (10, 15 e 20 minutos) e $M$. aegyptia (10, 15 e 20 minutos). Esse aumento no percentual de germinação proporcionado pelo ácido sulfúrico também foi observado por Stoller \& Wax (1974), Hardcastle (1978) e Horak \& Wax (1991) em Ipomoea hederacea, Ipomoea obscura Ipomoea pandurata, respectivamente. Ogunwenmo \& Ugborogho (1999) também constataram aumento de $100 \%$ na germinação de Ipomoea obscura, Ipomoea aquatica Ipomoea hederifolia quando usaram ácido sulfúrico concentrado. Entretanto, Moaisi \& Phillips (1991) não verificaram nenhuma eficácia na germinação de Ipomoea sinensis em razão do uso do ácido.

Observa-se também que os diferentes tempos de exposição das sementes ao ácido proporcionaram respostas contraditórias, provavelmente ocorridas devido à desuniformidade no tamanho das sementes e às características específicas de cada espécie (Groth, 2001). Ocorre que as sementes de menores tamanhos possivelmente tiveram seu embrião afetado pela ação do ácido e, conseqüentemente, o tratamento que recebeu aleatoriamente maior quantidade de sementes pequenas pode ter sido aquele que apresentou as respostas 
contraditórias nos resultados. As sementes não foram separadas por tamanho, a fim de manter uma condição mais próxima da que ocorre na natureza.

Esses tratamentos com ácido sulfúrico (Figura 2) também proporcionaram melhoria no índice de velocidade de germinação (IVG), pois a maioria dos tratamentos com aumento na germinação também apresentou maior IVG. Entretanto, isso indica que, possivelmente, o ácido tenha destruído a camada impermeável das sementes sem causar danos ao embrião, proporcionando germinação mais eficiente e rápida.
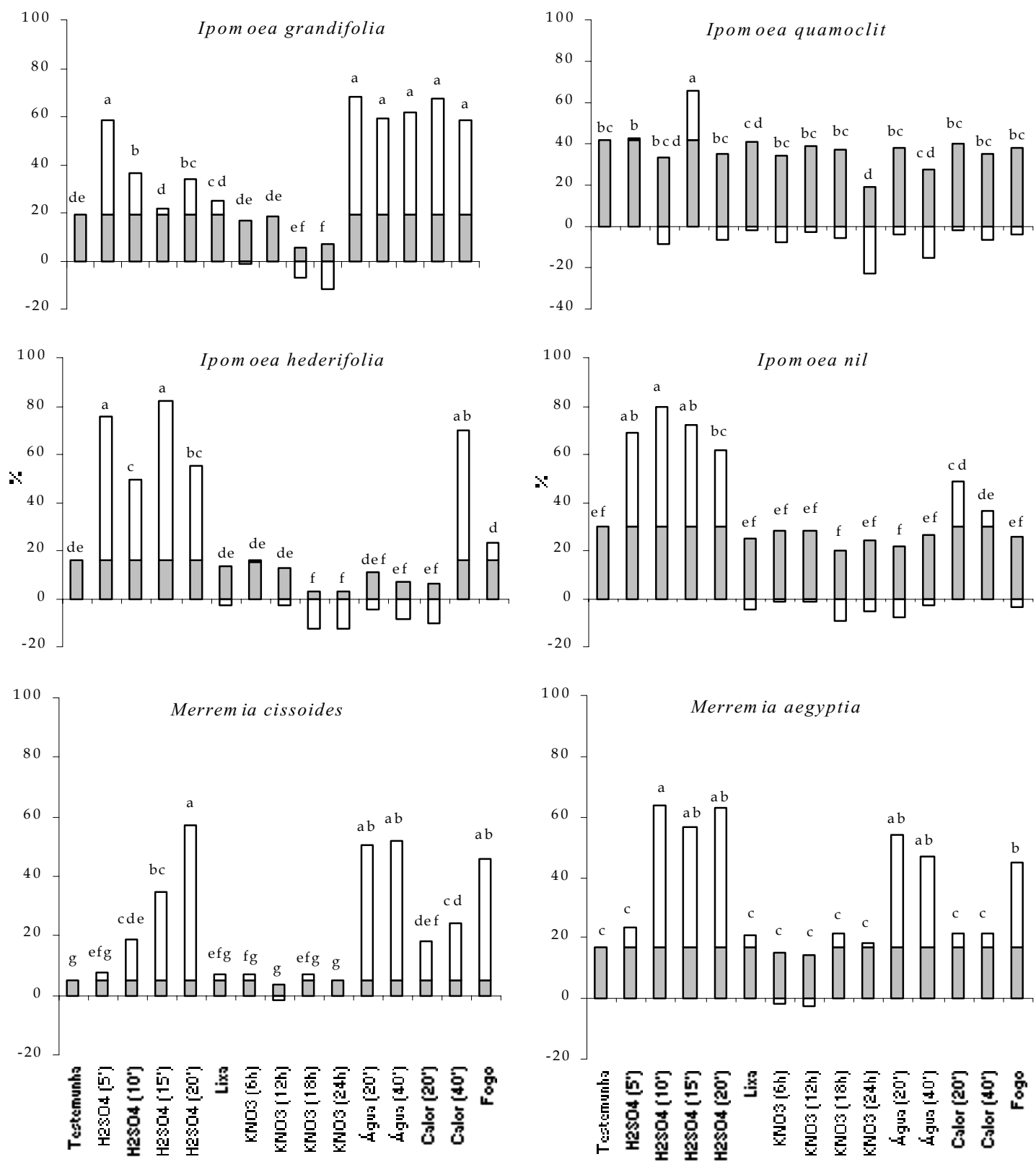

$\bigcirc \%$ germinação igual à testemunha $\bigcirc \%$ de germinação superior ou inferior à testemunha

Figura 1 - Percentual de germinação das sementes de Ipomoea grandifolia, Ipomoea quamoclit, Ipomoea hederifolia, Ipomoea nil, Merremia cissoides e Merremia aegyptia submetidas a diferentes métodos de superação de dormência. 

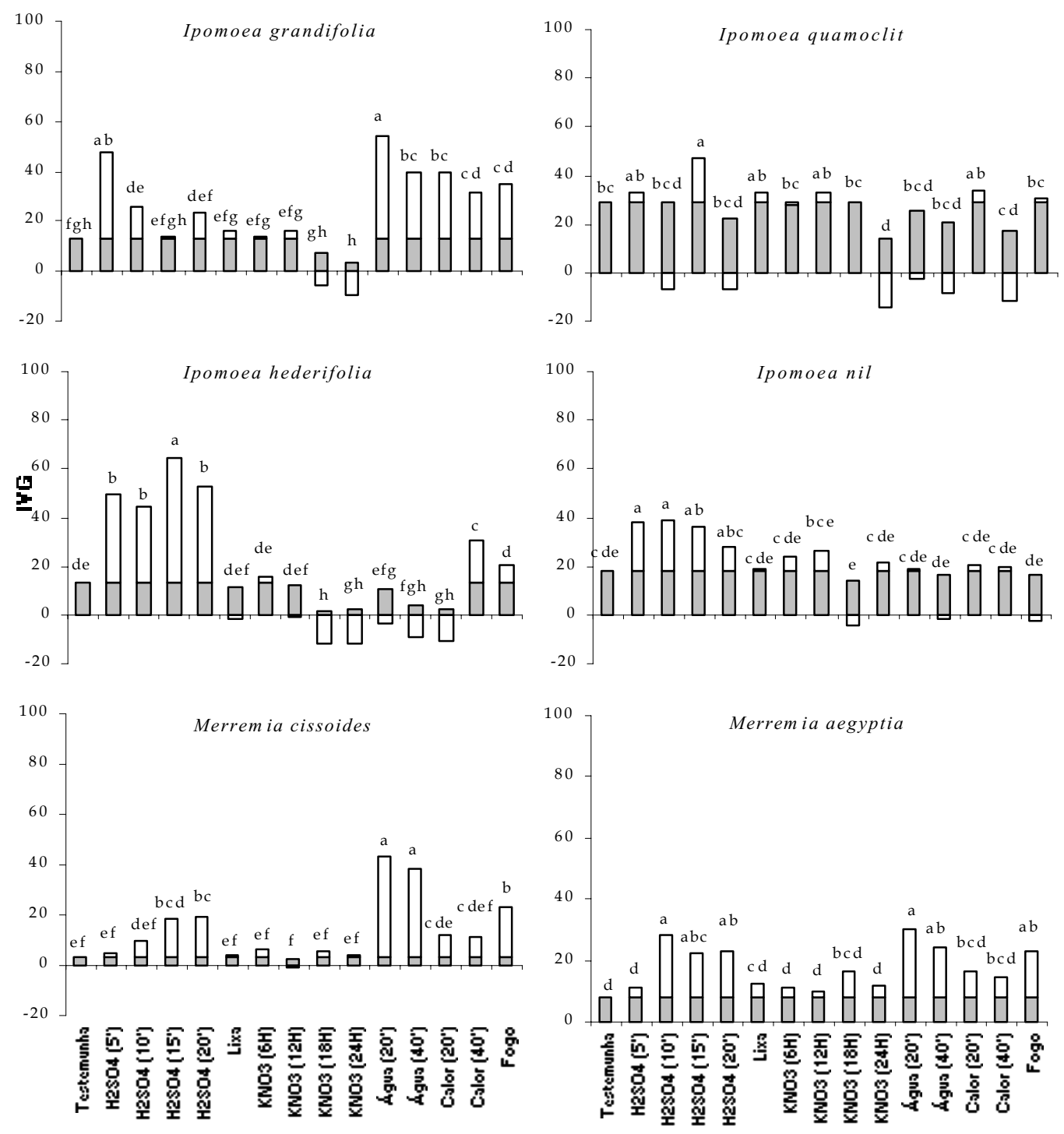

O IVG iguais a testemunha

O IVG superior ou inferior a testemunha

Figura 2 - Índice de Velocidade de Germinação (IVG) das sementes de Ipomoea grandifolia, Ipomoea quamoclit, Ipomoea hederifolia, Ipomoea nil, Merremia cissoides e Merremia aegyptia submetidas a diferentes métodos de superação de dormência.

O uso da lixa como escarificação mecânica proporcionou um pequeno acréscimo no percentual de germinação - porém não significativo - apenas da I. grandifolia, mas seu IVG não foi efetivo (Figuras 1 e 2). Esses resultados possivelmente podem ter ocorrido devido ao tempo de exposição e à intensidade da força das mãos sobre as sementes submetidas ao atrito com as lixas, especialmente as sementes pequenas, causando rachaduras no tegumento, que prejudicaram o embrião e, conseqüentemente, a germinação. Na literatura, Ogunwenmo \& Ugborogho (1999) verificaram eficácia da escarificação mecânica na germinação de Ipomoea obscura, Ipomoea aquatica, Ipomoea hederifolia, Ipomoea asarifolia e Ipomoea involucrata. A contradição entre os resultados da literatura e aqueles obtidos no experimento pode ser justificada pelas diferenças específicas entre as espécies testadas e reforçar a hipótese do tempo de exposição e da intensidade da força aplicada 
sobre as sementes no momento da escarificação.

A imersão das sementes em nitrato de potássio não foi efetiva para nenhum tratamento e nenhuma espécie; para I. quamoclit (24 horas de imersão), I. grandifolia e I. hederifolia (18 e 24 horas) ocorreu redução no percentual de germinação (Figura 1). Para todas as espécies (Figura 2), o IVG não foi efetivo, indicando que as sementes germinaram em intervalos longos uma das outras.

Nesses tratamentos, o tempo de embebição provavelmente foi o responsável pelos resultados obtidos, por ter causado a deterioração da camada impermeável das sementes e a conseqüente concentração do produto químico, intoxicação e morte do embrião. Moaisi \& Phillips (1991) também não observaram melhoria na germinação de Ipomoea sinensis embebidas durante 9 e 15 horas em nitrato de potássio, demonstrando que possivelmente esse produto químico não seja indicado às espécies de Ipomoea.

Entre os tratamentos que envolveram a imersão em água quente $\left(50^{\circ} \mathrm{C}\right)$, os resultados mais eficazes no que se refere ao aumento da germinação foram para I. grandifolia, $M$. cissoides e $M$. aegyptia, enquanto o calor seco foi eficaz para I. grandifolia, M. cissoides, I. hederifolia (apenas 40 minutos) e I. nil (apenas 20 minutos) (Figura 1). Provavelmente, o percentual de germinação não foi maior devido às diferenças entre espécies, pois Egley (1990) constatou acréscimo na germinação de Ipomoea lacunosa com temperaturas entre 40 e $60{ }^{\circ} \mathrm{C}$ e morte das sementes com temperaturas a partir de $70^{\circ} \mathrm{C}$.

A resposta do uso da temperatura na germinação das sementes pode estar relacionada com a constituição do tegumento. É possivel que o tegumento das espécies de I. grandifolia, $M$. cissoides e $M$. aegyptia possua características similares em suas constituições, pelo fato de o uso da água (20 ou 40 minutos) e do fogo apresentar respostas eficazes para as mesmas espécies. Esses tratamentos demonstraram ser efetivos na germinação dessas espécies; além da maior eficácia à germinação, também proporcionaram maior aumento no IVG (Figura 2), indicando que a água (20 ou 40 minutos) ou fogo quebraram a dormência sem danificar o embrião, que germinou mais rapidamente.

O uso da temperatura como calor seco $\left(50{ }^{\circ} \mathrm{C}\right)$ proporcionou maior germinação em um número maior de espécies, sendo calor durante 20 minutos para $I$. grandifolia, $M$. cissoides e I. nil e calor seco durante 40 minutos para I. grandifolia, I. hederifolia e $M$. cissoides (Figura 1). Entretanto, esses tratamentos foram menos eficazes porque o IVG (Figura 2) não foi efetivo para essas espécies, com exceção de I. grandifolia (calor seco por 20 e 40 minutos) e I. hederifolia (calor seco por 40 minutos). Possivelmente, o tegumento dessas espécies pode ter apresentado pequenas fissuras, responsáveis pelo lento desenvolvimento do embrião das sementes. Nesse caso, a abertura do tegumento, comentada por Baskin \& Baskin (1989), e as fendas observadas por Kim et al. (1990) podem ter sido insuficientemente profundas para garantir um contato mais intenso entre água e embrião e, conseqüentemente, maior germinação.

No entanto perante os resultados obtidos, pode-se concluir que o ácido sulfúrico promoveu aumento na germinação das sementes de todas as espécies - para I. grandifolia $(58,37$, 22 e $34 \%)$, I. hederifolia $(76,49,82$ e $55 \%)$, I. quamoclit $(43,33,66$ e 35\%), I. nil $(69,79$, 72 e $62 \%, M$. cissoides $(8,19,35$ e $57 \%$ ) e $M$. aegyptia $(24,64,56$ e $63 \%)$ - durante 5 , 10,15 e 20 minutos, respectivamente. A água (20 e 40 minutos), calor seco (20 e 40 minutos) e o fogo na superficie melhoraram a germinação para I. grandifolia $(68,59,62,67$ e 59\%), $M$. cissoides (50, 52, 18, 25 e 46\%) e $M$. aegyptia $(54,47,21,21$ e $45 \%)$, respectivamente. O calor seco de 20 e 40 minutos melhorou a germinação de $I$. nil (49 e 36\%), e o de 40 minutos, a de $I$. hederifolia $(70 \%)$. O uso de nitrato de potássio e lixa de parede não proporcionou melhoria na germinação das sementes.

\section{LITERATURA CITADA}

BASKIN, J. M.; BASKIN, C. C. Physiology of dormancy and germination in relation to seed bank ecology. In:

Ecology of soil seed banks. New York: Academic Press, 1989. $462 \mathrm{p}$

CARMONA, R. Problemática e manejo de bancos de sementes de invasoras em solos agrícolas. Planta Daninha, v. 10, n. $1 / 2$, p. $5-16,1992$. 
CHANDLER, J. M.; MUNSON, R. L.; VAUGHAN, C. E. Purple moonflower: emergence, growth, reproduction. Weed Sci., v. 25, p. 163-167, 1977.

EGLEY, G. H. Hight temperature effects on germination and survival of weed seeds in soil. Weed Sci., v. 38, n. 429435,1990 .

FELIPE, G. M.; POLO, M. Germinação de ervas invasoras: efeito da luz e escarificação. R. Bras. Bot., v. 6, p. 55-60, 1983.

GROTH, D. Caracterização morfológica de sementes de espécies invasoras da família Convolvulaceae Juss.

R. Bras. Sementes, v. 23, n. 2, p. 1-13, 2001.

HARDCASTLE, W. S. The influence of temperature and acid scarification duration on Ipomoea obscura Hassk. seed germination. Weed Res., v. 18, p. 89-91, 1978.

HORAK, M. J.; WAX, L. M. Germination and seedling development of bigroot Morningglory (Ipomoea pandurata) Weed Sci., v. 39, p. 390-396, 1991.

KIM, S. Y.; DE DATTA, S. K.; MERCADO, B. L. The effect of chemical and heat treatments on germination of Commelina benghalensis L. aerial seeds. Weed Res., v. 30, p. 109-116, 1990.
KISSMANN, K. G.; GROTH, D. Convolvulaceae Juss. In: Plantas infestantes e nocivas. 3.ed. São Paulo: BASF Brasileira, v. 2, 1992. p. 617-754.

LORENZI, H. J. Plantas daninhas do Brasil. 3.ed. São Paulo: Inst. Plantarum, 2000. p. 127-137.

MAGUIRE, J. D. Speed of germination - aid in selection and evaluation for seedling emergence and vigor. Crop Sci., v. 2, n. 2, p. 176-177, 1962.

MOAISI, K.; PHILLIPS, M. C. Breaking seed dormancy in some common arable weeds. Bull. Agric. Botswana, v. 9, p. 70-76, 1991. CD-ROOM

OGUNWENMO, K.; UGBOROGHO, R. E. Effects of chemical and mechanical scarification on seed germination of five species of Ipomoea (Convolvulaceae). B. Soc. Broteriana, v. 69, p. 147-162, 1999. CD-ROOM

ROLSTON, M. P. Water impermeable seed dormancy. Bot. Rev., v. 44, n. 3, p. 365-396, 1978.

STOLLER, E. W.; WAX, L. M. Dormancy changes and fate of some annual weed seeds in the soil. Weed Sci., v. 22, p. $151-155,1974$ 